\title{
Grand challenge of psychopathology in the years to come
}

\author{
Antoine Bechara ${ }^{1,2 *}$ and Xavier Noël ${ }^{3}$ \\ Department of Psychology, University of Southern California, CA, USA \\ 2 McGill University, Montreal, QC, Canada \\ ${ }^{3}$ Department of Psychiatry, Université Libre de Bruxelles, Bruxelles, Belgium \\ *Correspondence: bechara@usc.edu
}

It is an honor to begin our role as Co-Editors of 'Frontiers in Psychopathology', a new journal that aims for the promotion of multidisciplinary research that combines cognition and the mechanisms by which affect and emotion come to modify these cognitive states and vice versa, thus contributing to a variety of conditions associated with psychological suffering. Although behavioral research has long supported the dual process models of a more reflective, explicit, consciously deliberative system (System 2), and more impulsive, automatic, and implicit system (System 1) (Kahneman, 2003), psychopathology and cognitive neuroscience have uncovered credence to this duality in many conditions where abnormal functioning within the cognitive/brain processes underlying these dual systems, or their interactions, lead to a variety of psychopathological conditions. Especially important is the aim to understand the mechanisms underlying these implicit cognitive processes, which we define as introspectively unidentified (or inaccurately identified) traces of past experience, which can modulate feeling, thought, or action" (Geenwald and Banaji, 1995; De Houwer, 2006). In this realm, one can expect to make significant progress in advancing these explanatory models, which explore the relationship between attentional bias, a process that has long been rooted in experimental psychopathology, and memory bias, a process that has been rooted as well in basic memory or in social cognition research. The relative contribution of these processes to the genesis of explicit representations (e.g., craving for drugs), and their manipulation through cognitive processes related to working memory, represents an exciting avenue for years to come. More generally, there remains much work to do in order to identify those cognitive and affective processes as well as their brain substrate involved in the development of maladaptative actions (e.g., from drug use to addictive behavior).
In our opinion, little remains known about the phenomena of psychological suffering and cognitive processes that underpin it. However, the effort undertaken to establish a better clinical approach to these problems takes an interesting direction. For instance, craving episodes typically begin with apparently spontaneous thoughts about wanting or needing an appetitive target. This often occurs in the form of an affectively charged image of a reward target and its consumption (e.g., alcohol) (May et al., 2004). Such a thought then begins to linger in working memory to the extent that in an individual, for instance, with an alcohol-disorder, a simple verbal mention of alcohol can lead to a cascade of neurocognitive events that ultimately end up in impulsive drinking (Kavanagh et al., 2009). This is but one example of the many reasons why we hope that multidisciplinary research aimed at examining the interplay between cognition and emotion in clinical phenomena, which we would like to promote in this journal, will serve as a primary resource for years to come. Such an aim will certainly require contributions from work provided by researchers in several different disciplines including cognitive science, social, clinical and developmental psychology, as well as neuropsychology and behavioral neuroscience.

One of us (Antoine Bechara) recalls perfectly well in the early 1990s when he came to Iowa to study the decision-making capabilities of patients who have suffered injury to the ventromedial sector of their prefrontal cortex. At the time, the decision-making deficit seen in these patients presented a puzzling defect because their impairment was so obvious in their real life, but there was no laboratory probe to detect and measure this impairment. The reason was that all neuropsychology tests at the time were purely cognitive in perspective, and these patients happened to be intact cognitively speaking. This challenge was overcome, and progress was made in understanding the neurocognitive nature of this decision-making impairment after the development of what became known as the Iowa Gambling Task (IGT) (Bechara et al., 1994, 2000). At the time, the IGT was so unusual because it was not only cognitively complex, but it involved in a large part the use of reward and punishment during its performance. This was basically unheard of at the time, and skeptics were numerous in predicting its failure. However, it turned out that the development of the IGT enabled researchers, for the first time, to detect these patients' elusive decision-making impairment in the laboratory, measure it, and investigate its possible causes. This work has certainly drawn attention to the potential value in studying the neural basis of decision-making, and in bringing this question to the laboratory through the use of structured decision-making tasks involving choices that mimic real-life situations, in the way they factor uncertainty, reward, and punishment. Not only that, this line of work has gone beyond the boundaries of studying patients with neurological injury and proved to be valuable in understanding the underlying pathology of numerous psychopathological conditions, such as addiction, obsessive-compulsive disorders, impulse control disorders, bipolar disorders, anxiety disorders, and even eating disorders, to just name a few (Best et al., 2002; van Honk et al., 2002; Apkarian, et al., 2004; Bechara and Martin, 2004; Cavedini et al., 2004; Davis et al., 2004; Whitney et al., 2004; Jollant et al., 2005; Malloy-Diniz et al., 2007).

The IGT is only one example that illustrates the revolution from the strictly cognitive to the multidisciplinary cognitive-affective approach to understanding the underlying brain mechanisms of many psychopathological conditions. Although numerous tasks that employ behavioral assessments of affective states have been developed and are currently in 
use, the field as a whole is still, relatively speaking, in its infancy. For instance, there is now a flourishing science in novel areas such as "neuroeconomics", which relies on so many measures that tap into brain processes concerned with reward, punishment, valuation, and the like, but relatively so little has been applied from these newly emerging fields to various areas of psychopathology. This is such a significant and novel area that we hope to capture in our journal. Indeed, we would certainly like to cover in our journal all new advances in the use of behavioral measurements of affect-cognition, including those used in the "neuroeconomics" field, to understand the underlying brain dysfunction of specific psychopathological states. We see the past as primarily driven by conceptions rooted in cognitive theories. We see the future as a key period for significant advances in knowledge using multidisciplinary approaches that include measures of affect and emotion. However, our vision is not restricted to this area alone, but our philosophy is to be multidisciplinary no matter what. This is much to expect from contributions concerned with the interplay between cognitive neuropsychology, clinical psychology, experimental psychology, social psychology and brain sciences, applied principally to human psychopathology.

In addition, we would like to emphasize the fact that our grand challenge is not in just understanding basic mechanisms of psychopathological states, but also in translating available knowledge to potential therapies that minimize psychological suffering. For instance, following the hypothesis that the development of an addictive behavior parallels the increase in sensitized reaction to drug cues, which causes them to become highly salient, there is much to expect from new interventions directly targeting both automatic and non-automatic processes related to this complex phenomenon.

In sum, the Grand Challenge for psychopathology is to integrate biology, information processing, subjective experience, and therapeutic interventions, and understand how they relate to certain clinical phenomena, especially those in the realm of psychopathology. This journal will be a home to articles that advance knowledge and understanding of psychopathology, in terms of etiology and dynamics of change, for years to come. At this critical time, integrative approaches are viewed as the most promising avenue to understanding psychopathological states, and our ultimate aim is to have this journal as the key resource that promote such a research.

\section{REFERENCES}

Apkarian, A. V., Sosa, Y., Krauss, B. R., Thomas, P. S., Fredrickson, B. E., Levy, R. E., Harden, R. N., and Chialvo, D. R. (2004). Chronic pain patients are impaired on an emotional decision-making task. Pain 108, 129-136.

Bechara, A., Damasio, A. R., Damasio, H., and Anderson, S.W. (1994). Insensitivity to future consequences following damage to human prefrontal cortex. Cognition 50, 7-15.

Bechara, A., and Martin, E. (2004). Impaired decisionmaking related to working memory deficits in substance addicts. Neuropsychology 18, 152-162.

Bechara, A., Tranel, D., and Damasio, H. (2000). Characterization of the decision-making impairment of patients with bilateral lesions of the ventromedial prefrontal cortex. Brain 123, 2189-2202.

Best, M., Williams, J. M., and Coccaro, E. F. (2002). Evidence for a dysfunctional prefrontal circuit in patients with an impulsive aggressive disorder. Proc. Natl. Acad. Sci. U.S.A. 99, 8448-8453.

Cavedini, P., Bassi, T., Ubbiali,A., Casolari, A., Giordani, S. Zorzi, C., and Bellodi, L. (2004). Neuropsychological investigation of decision-making in anorexia nervosa. Psychiatry Res. 127, 259-266.
Davis, C., Levitan, R. D., Muglia, P., Bewell, C., and Kennedy, J. L. (2004). Decision-making deficits and overeating: a risk model for obesity. Obes. Res. 12, 929-935.

De Houwer, J. (2006). "What are implicit measures and why are we using them?" in Handbook of Implicit Coghnition and addiction, eds R. W. Wiers, and A. W. Stacy (Thousand Oaks, CA: Sage) 11-28.

Geenwald, A., and Banaji, M. (1995). Implicit social cognition: attitudes, self-esteem, and stereotypes. Psychol. Rev. 102, 4-27.

Jollant, F., Bellivier, F., Lobyer, M., Astruc, B., Torres, S., Verdier, R., Castelnau, D., Malafosse, A., and Courtet, P. (2005). Impaired decision-making in scuicide attempters. Am. J. Psychiatry 162, 304-310.

Kahneman, D. (2003). A perspective on judgment and choice. Am. Psychologist 58, 697-720.

Kavanagh, D. J., May, J., and Andrade, J. (2009). Tests of the elaborated intrusion theory of craving and desire: features of alcohol craving during treatment for an alcohol disorder. Br. J. Clin. Psychol. 48, 241-254.

Malloy-Diniz, L., Fuentes, D., Borges-Leite, W., Correa, H., and Bechara, A. (2007). Impulsive behavior in adults with attention deficit/hyperactivity disorder: characterization of attentional, motor and cognitive impulsiveness. J. Int. Neuropsychol. Soc. 13, 693-698.

May, J., Andrade, J., Panabokke, N, and Kavanagh, D. (2004). Images of desire: cognitive models of craving. Memory 12, 447-461.

van Honk, J., Hermans, E. J., Putman, P., Montague, B., and Schutter, D. (2002). Defective somatic markers in subclinical psychopathy. Neuroreport 13, 1025-1027.

Whitney, K. A., Fastnau, P. S., Evans, J. D., and Lysaker, P. H. (2004). Comparative neuropsychological function in obsessive-compulsive disorder and schizophrenia with and without obsessive-compulsive symptoms. Schizophr. Res. 69, 75-83.

Received: 26 March 2010; accepted: 31 March 2010; published online: 22 April 2010.

Citation: Bechara A and Noël X (2010) Grand challenge of psychopathology in the years to come. Front. Psychology 1:11. doi: 10.3389/fpsyg.2010.00011

This article was submitted to Frontiers in Psychopathology, a specialty of Frontiers in Psychology.

Copyright $\odot 2010$ Bechara and Noël. This is an open-access article subject to an exclusive license agreement between the authors and the Frontiers Research Foundation, which permits unrestricted use, distribution, and reproduction in any medium, provided the original authors and source are credited. 